\title{
Permakültür Çocuk Oyun Alanları
}

\section{Emir Müge ÜSKÜPLÜ ${ }^{1}$ (D) Zöhre POLAT ${ }^{* 1}$}

\section{${ }^{1}$ Aydın Adnan Menderes Üniversitesi, Ziraat Fakültesi, Peyzaj Mimarlığı Bölümü, Güney Yerleşke, AYDıN}

Öz: Permakültür "permanent culture", 'kalıcı kültür' ve "permanent agriculture" 'kalıcı tarım' kavramlarından oluşmuştur. Genel olarak permakültür, doğaya göre modellenen bir tasarım sistemi olarak tanımlanmıştır. Permakültür aynı zamanda doğayı, doğal değerleri korumayı, onarmayı, bu değerlerde planlamayı, tasarımı ve yönetimi destekleyen bir felsefedir. Bu felsefe peyzaj mimarlığı çalışma alanlarına da yansımaktadır. Permakültür, açık ve yeşil alanların daha sağlıklı, yaratıcı ve sürdürülebilir olmalarına yardımcı olacak teknikler ve ilkeler ortaya koymaktadır. Bu çalışmanın amacı çocuk oyun alanlarında permakültürün yansımasını değerlendirmektir.

Dış mekânda oyun oynamanın çocuklar üzerinde fiziksel, sosyal ve bilişsel birçok faydası bulunmaktadır. Çalışmada doğa, çocuk ve oyun kavramlarına odaklanılarak, çocuk oyun alanları permakültür felsefesiyle bütünleştirilmiştir. Oyun oynadığı doğal ortamı keşfeden ve farkında olan bir çocuğun, daha sonra peyzajın doğal ve kültürel elemanlarına değer vermeye başlayacağı önemsenmiştir.

Yapılan araştırmalar sonucu elde edilen veriler, dünya genelinde çocuk oyun alanlarında peyzajın doğal elemanlarının baskın olduğu oyun alanlarııın tasarlandığını ve bu tasarımların uygulandığını göstermektedir. Çalışmada Türkiye' de de çocuk oyun alanlarında doğal oyun elemanlarının ve sanatsal aktivitelerle oyun senaryolarııın kullanılacağı çocuk oyun alanları tasarımları ile ilgili öneriler sunulmuştur.

Anahtar Kelimeler: permakültür çocuk oyun alanları, doğa ve oyun, oyun ve peyzaj tasarımları

\section{Permaculture Children Playgrounds}

Abstract: Permaculture is composed of the concepts of "permanent culture" and "permanent agriculture". In general, permaculture is defined as a design system modeled according to nature. Permaculture is also a philosophy that supports nature, protection, restoration, planning and management of natural values. This philosophy is reflected in the researches of landscape architecture. Permaculture techniques and principles help open green spaces planning and design. In this study, the reflection of permaculture in children's playgrounds was evaluated. Outdoor play has many physical, social and cognitive benefits for children. In this study, focusing on nature, children and play concepts, children's playgrounds are integrated with permaculture philosophy. It was cared that a child who discovers and is aware of the natural environment in which he plays, will then begin to value the landscape elements.

Results of the researches show that the playgrounds where the natural elements of the landscape are dominant in children's playgrounds around the world are designed and applied. The researche presents recommendations regarding the design of playgrounds for children to use the natural play elements in a children's playground and play scenarios with art.

Keywords: permaculture children playgrounds, nature and play, play and landscape designs

\section{GiRiş}

Permakültür "permanent culture" 'kalıcı kültür' ve "permanent agriculture" 'kalıcı tarım' ın kısaltması olan kelime Bill Mollison ve Mollison' un ilk öğrencilerinden David Holmgren tarafından kullanılmıştır. Mollison 1970'lerde Holmgren ile birlikte, doğaya ve yerli kültürlerle ilgili gözlemlerini değerlendirirerek, bu ekosistemleri zengin ve sürdürülebilir kılan ilkeleri araştırmıştır (Hemenway, 2007; Bulut ve Yılmaz, 2008; Ar ve Uğuz, 2014). Permakültür dünyaya bakışın başka bir yolu olmuştur (Pezrès, 2010; Aiken, 2017). Permakültürde, doğayla yeniden bağlantı kurmak ve insanı doğanın içinde var etmek temel amaçtır (Praetorius, 2006; Stark, 2009; Rhodes, 2012; Doherty, 2018). Ferguson ve Lovell (2014)'e göre çağdaş kullanımında, "permakültür" terimi, birbirinden ayrı fakat birbiriyle ilişkili dört farklı anlam içermektedir. Bunlar; bir tasarım metodolojisi, bir yöntem ve teknik havuzu, sosyal bir hareket ve sosyal bir felsefedir. Permakültür bir uluslararası sürdürülebilirlik hareketi ve agroekolojik tasarım sistemidir (Hirschfeld ve Acker, 2019).

Doğa, çocuk ve oyun bağının önemine odaklanan çalışmanın amaçları; (1) Doğa içinden, doğal elemanlarla oyunun çocuklar için önemini sunmak, (2) Peyzaj mimarlığında, çocuk oyun alanları tasarımlarında, peyzajın doğal elemanları ile tasarlanmış çocuk oyun alanlarının felsefesini taşıyan permakültür çocuk oyun alanları ile ilgili bilgiler sunarak, permakültür çocuk oyun alanlarının tasarlanması ve bu alanlardaki doğa ve sanatla oyun senaryoları ile ilgi öneriler sunmaktır.

\section{PERMAKÜLTÜR KAVRAMI}

Kentsel ekosistemlerde, ekosistem dengelerinde bozulmalar yaşayan sistemler; topraklar, rekreasyonel alanlar,

Sorumlu Yazar: zohre.polat@adu.edu.tr

Geliş Tarihi: 24 Mayıs 2019

Kabul Tarihi: 13 Aralık 2019 
atmosfer ve besin döngüleridir (Mollison,1981; Veteto ve Lockyer, 2008). Permakültür kavramı, yaşam alanlarımızda ekosistemler kurgulamayı önermektedir (Mollison, 19988; Mollison, 1996; Holmgren, 2002; Holmgren, 2007). Örneğin Fukuoka'nın, kurduğu çiftlik, doğayı ve insan yaşamını bütün olarak değerlendiren bir sistemdir (Korn, 2003). Permakültür alternatif ekonomi, doğal yapı, enerji sistemleri, su sistemleri, ekolojik restorasyon, topluluk gelişimi, eğitim vb. alanlarda kullanılan bir kavramdır (Haluza-DeLay ve Berezan, 2013).

Permakültür kavramı ve felsefesi tarım (Mollison ve Holmgren, 1978), eğitim (Praetorius, 2006), endüstri (Jelinek, 2017), mühendislik (Bogatyrev ve Bogatyreva, 2015), turizm (Tatar ve Olay, 2015), peyzaj tasarımı (Bulut ve Yılmaz, 2008; Polat, 2018), planlama (Bilgi, 2013), yönetim (Akhtar ve ark., 2016) ve koruma (Hirschfeld ve Acker, 2019) gibi birçok diğer bilimsel alanda yapılan araştırmalarda yol gösterici olmuştur (Salleh ve ark., 2018). Permakültür aynı zamanda doğayı, doğal ve kültürel değerleri korumayı, onarmayı, bu değerlerin sürdürülebilirliği için planlamayı, tasarımı ve yönetimi destekleyen bir felsefedir. Bu felsefe peyzaj mimarlığı çalışma alanlarına da yansımaktadır. Bu nedenle çalışmada çocuk oyun alanlarında permakültürün yansıması değerlendirilmiştir.

\section{ÇOCUK VE OYUN}

Oyun çocuğun özerk kimliğinin keşfedilmesi için çok önemli olan aktivite, yapıcı bir güç olarak kendini göstermektedir (Hayward ve ark., 1974; Ginsburg, 2007; Bulut ve Kılıçaslan, 2011).

Açık hava oyunları, çocukları doğaya, hayvanlara ve bitkilere yönelten oyunlardır (Canlı, 2014). Fiziksel aktiviteler ve oyun, çocukların motor koordinasyonlarını geliştirerek bilişsel gelişimlerinin de zenginleşmesine katkıda bulunan önemli etkinliklerdir. Dış mekân oyunları çocuklara doğal alanlar sunması nedeniyle çocuğun hayatında önemli bir destektir (Sarı, 2011; Pesce ve ark., 2016; Arslan ve Dilci, 2018). Huizinga (1995)'e göre günümüz koşullarında çocukların dış mekânda oyun oynama şansı gün geçtikçe azalmaktadır. Bu nedenle çocuklar mutlaka dış mekânda oyuna yöneltilmelidir.

\section{ÇOCUK OYUN ALANLARI}

Çocukların özgürce kendilerini ifade ettikleri alanlar çocuk oyun alanlarıdır (Aksoy, 2011). Çocuk oyun alanları çocukların sosyal, duygusal, bilişsel ve fiziksel gelişimi ile eğitimleri için gerekli olan aktivitelerini desteklemek için tasarlanmış bir eğitim ortamıdır. Bu alanlar, kentsel açık/yeşil alan sistemi içerisinde çok önemli alanlardır (Powell, 2005). Günümüzde çocukların fiziksel oyun ortamları ve oyun oynama olanakları değişmektedir ve ücretsiz oyun oynama olanakları azalmaktadır (Fjortoft, 2004). Sandseter ve Kennair (2011)' e göre; günümüzde bazı oyun alanları çocukları korkabilecekleri bazı durumlara maruz bırakmaktadır.

\section{Çocuk Oyun Alanı Değişimleri}

Heseltine ve Holborn (1987)'e göre, Dünya Çocuk Yılı nedeniyle 1977 yılında açıklanan Çocuk Oyun Hakları Malta Deklarasyonu'nda, oyunun, beslenme, sağlık, barınma ve eğitim vb. temel gereksinimler gibi yaşamsal önemi olduğu vurgulanmaktadır. Dünyada ve Türkiye'de çocuk oyun alanları tarihten günümüze değişim ve dönüşüm içindedir. Çocuk oyun alanları tasarım ve uygulamaları yıllar içerisinde değişim göstermektedir (Şekil 1 ) (Anonim 2019a).

1970-1980'lerde oyun alanlarındaki güvenlik ile ilgili endişelere yanıt olarak yuvarlak kenarlar ve sert plastik ekipmanlardan oluşan standartlaşmış oyun alanları tasarlanırken, 1980'lerden günümüze kadar ise zemin kaplamaları güvenli, çeşitli temalar ve oyun ekipmanlarından oluşan yaratıcı modern oyun alanları tasarlanmıştır (Yao, 2015; Polat, 2018).

Çocuk oyun alanları ve ekipmanlarının tasarımı, farklı yaş gruplarının farklı oyun ihtiyaçları ve fiziksel yapıları olması nedeniyle, yaş gruplarına göre değişim göstermektedir. Çocuk oyun alanları; 0-5 yaş grubu, 6-10 yaş grubu, 11-15 yaş grubu ve $16-18$ yaş grubu için ayrı oyun alanları olarak değerlendirilmiştir. Birleşmiş Milletler Uluslararası Çocuklara Yardım Fonu (UNICEF) 'na göre çocukluk sınırı 18 yaş olarak belirlenmiştir (Yao, 2015).

Oyunun çocuk için önemi, çocuk oyun alanlarıyla ilgili yürütülen birçok bilimsel araştırma ile yansıtılmaktadır. Bu araştırmalar arasında; "Dış Mekânda Çocukluk: Peyzajın Sosyal Ekolojisine Doğru" (Moore ve Young, 1978), “Oyun
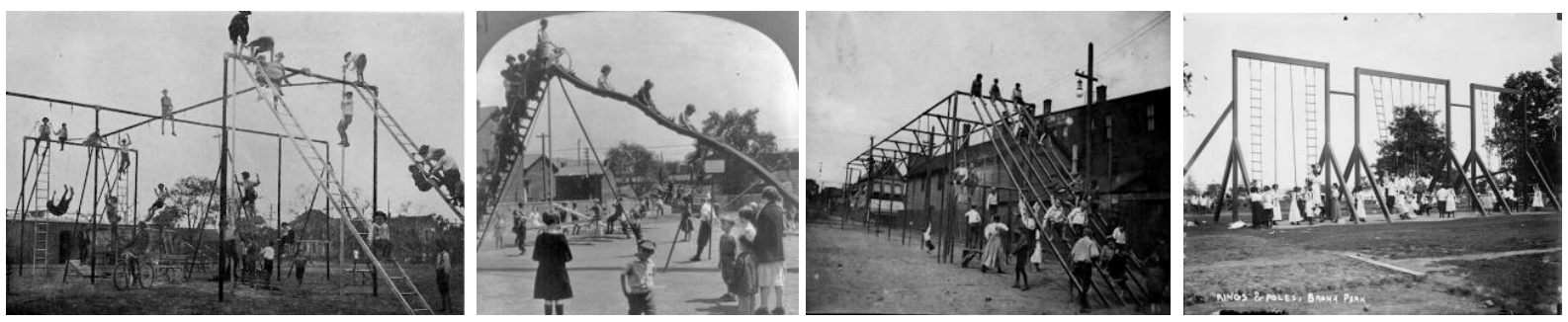

Şekil 1. Trinity Play Park'ta oyun alanı ekipmanı üzerinde oynayan çocuklar 
Alanı Tasarımları ve Okul Öncesi Çocuk Davranışları" (Brown ve Burger, 1984), "Ağa Bağlı Manzaralar: Oyun Alanını Yeniden Tanımlama" (Navarro, 2018) ve "Oyun Alanını Kodlamak: Çocukluk Sınıflarında Olumlu Öğrenme Deneyimlerini Teşvik Etmek" (Bers ve González-González, 2019) yer almaktadır.

\section{ÇOCUK, DOĞA ve OYUN}

Çocukluk döneminden itibaren geçirilen aktif doğa deneyimlerinin, çocukların doğal varlıklarla güçlü empatik ilişki kurmalarını sağladığı, çevre algılarını şekillendirdiği, ekolojik benliklerinin oluşmasında belirleyici olduğu ve çocukların ekolojik yapıyla olan etkileşimlerinin arttığı ortaya konulmuştur (Cohen ve Horm-Wingerd, 1993). Çocuk için doğal oyun alanları iyi bir öğrenme alanı olduğu kadar, iyi bir pedagojik çevredir (Pollard ve ark., 1997). Doğanın merkezde yer aldığı bir sistemde; çekirdeğini çocuğun oluşturduğu, kültür, medya, eğitim, ekonomi ve sosyallik ağı vardır. Doğal alanlardan yoksunluk çocuğu doğaya yöneltmektedir (Freeman ve Heezik, 2018). Araştırmalar, özellikle doğal oyun alanlarında, dış mekânda oynamanın çocukların fiziksel aktivitesini artırdığını ve çocuklukta obeziteyi potansiyel olarak azalttığını göstermektedir (Herrington ve Brussoni, 2015). Şekil 2'de doğal oyun elemanlarıyla tasarlanmış çocuk oyun alanlarına örnekler sunulmuştur (Anonim, 2019b).

Yapılan bir araştırmanın sonucuna göre, ebeveynler doğal oyun alanlarının düşük riskli ve görsel olarak da daha çekici olduğunu belirtmiştir (Wang ve ark., 2018). Nicholson Moore 1996'e göre doğada oynayan çocukların birbirleriyle ilgili daha olumlu hisleri vardır (White, 2004). Önerilen oyun ortamlarının temel bileşenleri; su, ağaçlar, çalılar, çiçekler, çocukların keşfedebileceği ve etkileşime girebileceği uzun otları içeren doğal bitki örtüsü, göletlerdeki canlılar, kelebekler, böcekler vb. hayvanlar, kum ve su ile oluşan karışımlar, renk çeşitliliği, dokular ve malzemeler, değişen mevsimleri, rüzgârı, ışığı, sesleri ve hava koşullarını tecrübe etme şansı yakalayacakları alanlar, oturmak, dayanmak, tırmanmak, barınma ve gölge sağlamak için doğal alanlar, alan plastiği ve köşeler, sosyalleşmeyi destekleyen alanlar, mahremiyeti olan alanlar, hayallerinde değiştirilebilecekleri yapılar ile diğer donanım ve malzemelerdir (White ve
ÜSKÜPLÜ EM, POLAT Z Stoecklin, 1998). Son yıllarda özellikle doğal ortamda doğal elemanlarla oyun birçok bilimsel araştırmanın konusu olmuştur. Çocuk doğa ve oyun ile ilgili bilimsel araştırmalar Çizelge 1'de sunulmuştur.

Dış mekânda oyun oynamanın çocuklar üzerinde fiziksel, sosyal ve bilişsel birçok faydası bulunmaktadır. Bu faydalar; duygu düzenlemenin geliştirilmesi (Lester ve Russell, 2008), özgüven kazandırma (Bulut ve Kılıçaslan, 2011), doğayı, hayvanları ve bitkileri tanıma (Canlı, 2014), fiziksel aktivitelerle akademik başarıyı artırma (Haapala ve ark., 2014), motor koordinasyonlarının zenginleşmesi ve bilişsel gelişim sağlanması (Pesce ve ark., 2016) ve hayata hazırlamak (Arslan ve Dilci, 2018) olarak vurgulanmaktadır.

\section{PERMAKÜLTÜR KAVRAMI ve ÇOCUK OYUN ALANLARI}

Permakültür, son yıllarda tarım, şehir ve bölge planlama, mimarlık, peyzaj tasarımı çalışmalarına yansıyan, doğaya uygun çok yönlü ilişkiler kurma konusunda yerelleşmiş, sürdürülebilir ve kalıcı bir yaklaşımdır (Wallace ve Carruthers, 2018).

Permakültürün tanımı ve ilkeleri sürekli olarak gelişmektedir ve peyzaj mimarlığı meslek disiplininin ilkeleri ile örtüşmektedir. Permakültür, açıkyeşil alanların daha sağlıklı, yaratıcı ve sürdürülebilir olmalarına yardımcı olacak teknikler ve ilkeler ortaya koymaktadır. Bu bağlamda açık/yeşil alanlarda permakültür tasarımı ile toprak ve doğal yaşam ilkesinin toplum hayatına tekrar kazandırıması ve kentlerde toplum içindeki bağların ve değerlerin zenginleşmesini sağlayacaktır (Najafidashtape ve Hamamcıoğlu, 2018). Permakültür kavramı peyzaj mimarlığında planlama, tasarım, onarım, koruma, uygulama ve yönetim çalışmalarının hem içinde olan hem de farklı bakış açılarıyla desteklenebilecek bir kavramdır. Permakültür, kentsel açık/yeşil alanlarda tasarımın bir bütün olarak ele alınmasını sağlamaktadır (Najafıdashtape ve Hamamcıoğlu, 2018).

Permakültürün görülen ve görülmeyen iki bileşeni vardır. Altyapı olarak tanımlanabilecek yapılar, bitki sistemleri, hayvanlar ve arazi plastiği permakültürün görülen unsurlarını, sosyal sistemler olarak tanımlayabileceğimiz kültür, arazi kullanımı, yasalar ve eğitim ise permakültürün görülmeyen unsurlarını oluşturmaktadır (Stark, 2009).
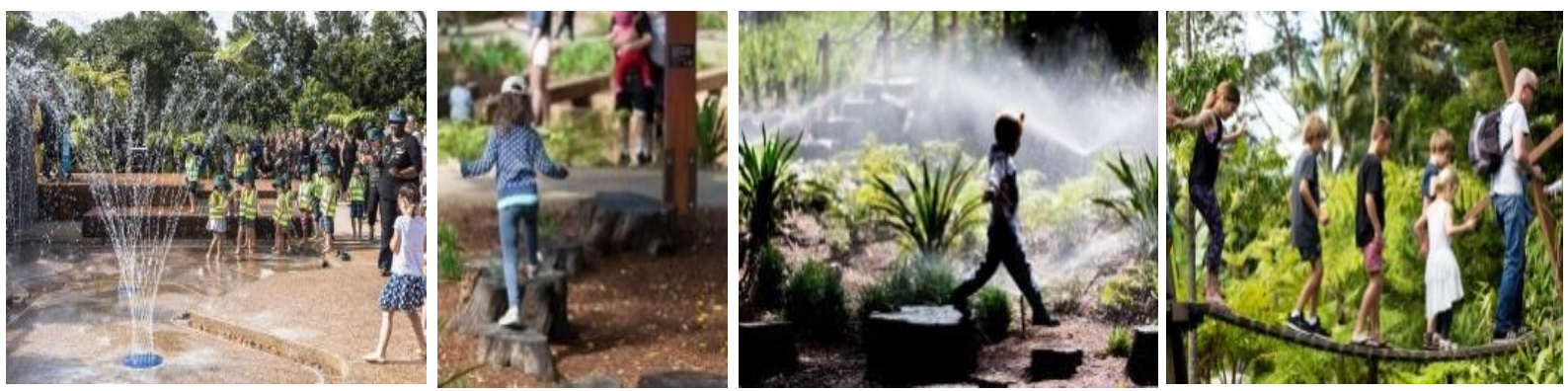

Şekil 2. Doğal oyun elemanlarıyla tasarlanmış çocuk oyun alanları 
Çizelge 1. Çocuk, doğa ve oyun ile ilgili araştırmalar

ARAŞTıRMA
Gelişim psikolojisi ve biophilia hipotezi: Çocukların doğa ile ilişkisi
Çocuklar için bir oyun alanı olarak doğal çevre: Peyzaj tanımı ve doğal
oyun alanının analizi
Doğayla iç içe: Yeşilliğin çocukların bilişsel işlevlerine etkileri
Çocuk oyun alanı olarak doğal çevre: Okul öncesi çocuklarda açık hava
oyun aktivitelerinin etkisi
Küçük çocukların doğa ile ilişkisi: Çocukların gelişimi ve dünyanın
geleceği için önemi
Çocukların oynamaları ve öğrenmeleri için peyzajda: Doğal akarsu ve
oyun parkı arasında kavramsal bir karşıştırma
Sürdürülebilir toplum için yeni bir tasarım yaklaşımı olarak permakültür
çocuk oyun alanları
Ingiltere'de okul çağındaki çocuklarda oyun alanı ve doğa temelli oyunun
fiziksel aktivite ve özgüvene etkisi
Çocukların fiziksel aktivite düzeyleri, geleneksel ve doğal oyun
alanlarının kullanımı
Fiziksel aktivitenin ötesinde: Çocuk sağlığı ve gelişimi için oyun ve doğa
tabanlı oyun alanlarının önemi

KAYNAK

(Kahl, 1997)

(Fjortoft ve Sageie, 2000)

(Wells, 2000)

(Fjortoft, 2001)

(White, 2004)

(Said ve Bakar, 2005)

(Bulut ve Yılmaz, 2008)

(Barton ve ark., 2015)

(Coe ve ark., 2014)

(Herrington ve Brussoni, 2015)

Çocuk oyun alanı ortamlarının yeniden yapılandırılması: Doğa, oyun alanı özellikleri ve oyun süresi deneyimleri

(Bagot ve ark., 2015)

Bugünün oyun alanlarının permakültür oyun alanı ile ilke ve tasarım açısından değerlendirilmesi: Aydın, Türkiye örneği

(Polat, 2018)

Küçük çocuklar ve yetişkinlerin doğal oyun alanı algıları: Güneybatı Çin'in Chengdu örneği

Çocuklar, doğa ve şehirler: Bağlantıları yeniden düşünmek

(Wang ve ark., 2018)

(Freeman ve Heezik, 2018).

Doğadaki çocuklar: Duyusal katılım ve biyoçeşitlilik deneyimi

(Beery ve Jørgensen, 2018)

Kentte yeşil alanlarda oynayan çocukların fiziksel aktiviteleri ve sosyal (Raney ve ark., 2019) davranışları

Doğal elemanlarla oyun oynama önerileri ile gelişen permakültür çocuk oyun alanları tasarımı, Simonon (2000) tarafından ortaya konulmuştur.

Louv (2010)' a göre günümüzde çocukların gelişimlerini destekleyen doğal oyun alanlarının olmaması ve ebeveynlerin doğayı tanıma konusunda çocuklarına yeterince model olmaması, çocukların doğadan izole yaşamalarına neden olmaktadır. Bu olgu "Doğa Yoksunluğu" olarak tanımlanmıştır (Taştepe ve ark., 2016). Çocukların doğa ile etkileşimde bulunması, ekolojik çeşitlilik kavramının bilişsel olarak yapılandırılmasına olanak sağlamaktadır (Seefeldt ve Galper, 2007). Bu yöntem çocukluk dönemi, ergenlik ve yetişkinlik dönemi için birbirine bağlı bir ağ oluşturacaktır.

Kellert (2002)' e göre oyun oynadığı doğal ortamı keşfeden ve farkında olan bir çocuk, daha sonra peyzaj elemanlarına değer vermeye başlamaktadır. Çocukların doğal oyun elemanları ile oynaması bilişsel, sosyal, fiziksel ve duygusal birçok değer kazandırmaktadır. Bunun yanı sıra doğal oyun elemanlarıyla oyunun modüler oyun elemanlarından daha faydalı olduğu birçok araştırmada (Fjortoft ve Sageie, 2000; Coe ve ark., 2014; Herrington ve Brussoni, 2015) vurgulanmıştır.

Walsh (2016)' a göre, IPA (The International Play Association- Dünya Uluslararası Oyun Birliği), 1979 yılında Uluslararası Çocuk Yılı tarafından yaratılan değişimin sürdürülmesine odaklanarak, çocuğun hayatının gelişimi için dünya görüşü oluşturmaya odaklanılmalıdır. Eğitim ile aynı amaçlara yönelik olan oyun hakkı bilinci, toplumu ve yönetimleri bu hakkın kullanılmasını teşvik etmelidir.

Çocukların oyun alanlarında en çok tercih ettikleri çevresel özellikler; doğadaki renkler, ağaçlar, ormanlık alanlar, değişen topoğrafya, gölgeli alanlar ve çayırlardır. Tırmanmak, oyun ekipmanlarıyla inşaat yapabilecekleri 
alanları ve diğer mekânları keşfetmek, deneyimlemek için zorlu mekânlar oyun için vazgeçilmez aktivitelerdir (Fjortoft, 2004).

\section{PERMAKÜLTÜR ÇOCUK OYUN ALANLARI TASARIM ELEMANLARI: DOĞA VE SANATLA OYUN SENARYOLARI}

Polat (2018)'e göre permakültür çocuk oyun alanları tasarım elemanları ve senaryoları bitkiler, hayvanlar, kuşlar, böcekler vb. hayvanlar, su (hareketli ve durgun), su dansı, toprak, çakıl taşları, kum ve kum oyunu alanları, topoğrafya, talaş, ahşap materyal ve elemanlar, rüzgâr, yağmur, kar ve temiz havada oyun, yürüyüş ve koşu alanlarından oluşmalıdır. Gemmell (2015)'e göre oyun alanlarında kazı alanlarına yer verilmeli, çevre ile bağlar kurulmalıdır. Yine Walsh (2016)'ya göre oyun için sessiz oyun alanı, gizli, özel oyun için alanlar ve ortak kullanım alanları da yer almalıdır.

Dünya genelinde yapılan araştırmaların sonuçları, peyzajın doğal elemanlarının baskın olduğu çocuk oyun alanlarının tasarlandığını ve uygulandığını göstermektedir. Türkiye' de de çocuk oyun alanlarında doğal oyun elemanlarının ve oyun senaryolarının kullanılacağı çocuk oyun alanları tasarlanmalıdır.

Polat (2018), Gemmell (2015)'e ve Walsh (2016)'ın önerdikleri doğal oyun elemanları değerlendirilerek permakültür oyun alanlarında oyun için alternatifler sunulmuştur:

*Bitkilerin çeşitli oyunlar için tasarlanması (saklambaç, sessiz oyun, eğimli çim yüzeylerde kaydırak, ağaç kovukları ve oyun, ağaçlara tırmanma vb.).

*Su ve ahşap elemanlarla oyun için tasarımlar (Ahşap su kuyuları, ahşap işleme, ışıklı su oyunları, su değirmenleri, çeşmeler ve yağmurla oyun vb.).

*Karda oyunlar, resim panoları ve kara tahtalar, toprak, kum ve çamurla oyun, seramik çalışmaları, heykellerle oyun ve müzikle oyun vb.

*Ekolojik eğitim için oyunlar (Bitki ve hayvanları tanıma panoları, rüzgar tribünleri, güneş enerjisi panelleri, kuş gözleme kuleleri, peyzajı izleme kuleleri, fotoğraf çekimi vb. faaliyetler).

\section{SONUÇ}

"Permakültür Oyun Alanları" planlama, tasarım ve yönetim ağı ile kurgulanmalıdır. Peyzaj mimarlığı araştırmaları permakültür fesefesini ve ilkelerini içermektedir. Gerçekte permakültür peyzaj mimarlığı meslek disiplinin ilkelerinin özünü yansıtmaktadır. Çocuk oyun alanlarında doğal elemanlarla ve sanatla oyun ile ilgili öneriler aşağıda sunulmuştur;

*Dünyadaki oyun alanı değişim dönemlerinden modüler sentetik oyun elemanları baskın dönemi yaşayan Türkiye'de, doğal elemanlarla oyunun çocuklara faydalarına odaklanılarak, doğa baskın oyun alanı döneminin yaşanması Barton J, Sandercock G, Pretty J, Wood C (2015) The Effect of Playground-and Nature-Based Playtime interventions on Physical Activity and Self-Esteem in
ÜSKÜPLÜ EM, POLAT Z

gerekmektedir. Bu çalışmada bu dönem permakültür çocuk oyun alanları dönemi olarak adlandırılmıştır. Türkiye'de bu değişimin sağlanması için ilk adım olarak modüler oyun elemanları ile birlikte tasarlanacak olan doğal oyun elemanları, doğa ile oyunu adım adım destekleyecektir.

*Bu değişim ve dönüşümün sağlanması için, gerekli kurumlar ve yerel yönetimler doğa ve oyun ile ilgili bilgilendirilmelidir.

*Çalışmada sunulan permakültür oyun elemanları ve oyun senaryoları çocuk oyun alanı tasarım ilke ve öğeleri ile birlikte değerlendirilmelidir.

*Eğitim sisteminde permakültür ve doğal elemanlarla oyun gibi kavramlar mutlaka desteklenmelidir.

Permakültür çocuk oyun alanları, kentsel ekosistemde çocukların yaşamlarını doğa ile anlamlandırıp, kimlik kazanacakları yeşil alanlar olacaktır.

\section{KAYNAKLAR}

Aiken G (2017) Permaculture and the Social Design of Nature. Geografiska Annaler: Series B, Human Geography, 99(2): 172-191.

Akhtar F, Lodhi SA, Khan SS, Sarwar F (2016) Incorporating Permaculture and Strategic Management for Sustainable Ecological Resource Management. Journal of Environmental Management, 179: 31-37.

Aksoy Y (2011) Çocuk Oyun Alanları Üzerine Bir Araştırma İstanbul, Isparta, Eskişehir, Erzurum, Kayseri, Ankara, Zonguldak ve Trabzon illeri Örneği. İstanbul Aydın Üniversitesi Mühendislik Mimarlık Fakültesi Mimarlık Bölümü, 106.

Anonim (2019a).Dangerous playgrounds from the 1900s would give parents today heart failure.https://thefederalistpapers.org/us/dangerousplaygrounds-1900s-give-parents-today-heart-failure. (Erişim tarihi: 20. 05. 2019).

Anonim (2019b). Ian Potter children's wild play. http://www.landezine.com/index.php/2017/12/ianpotter-childrens-wild-play-by-aspect-studios/. (Erişim tarihi:20. 05. 2019).

Ar H, Uğuz SÇ (2014) Sürdürülebilir Turizm Çerçevesinde Gönüllü Turizmi ve Permakültür İlişkisi: Permakültür Çiftlik ve Köy Uygulamaları. Proceedings of VII. Lisansüstü Turizm Öğrencileri Araştırma Kongresi, 222-232.

Arslan A, Dilci T (2018) Çocuk Oyunlarının Çocukların Gelişim Alanlarına Yönelik Etkilerinin Geçmiş ve Günümüz Bağlamında İncelenmesi (Sivas ìli Örneklemi). Fırat

Bagot KL, Allen FCL, Toukhsati S (2015) Perceived Restorativeness of Children's School Playground Environments: Nature, playground Features and Play Period Experiences. Journal of environmental psychology, 41: 1-9.

UK School Children. International journal of environmental health research, 25(2): 196-206. 
Beery T, Jørgensen KA (2018) Children in Nature: Sensory Engagement and the Experience of Biodiversity. Environmental Education Research, 24(1): 13-25.

Bers MU, González-González C, Armas-Torres MB (2019) Coding as a playground: Promoting positive learning experiences in childhood classrooms. Computers \& Education, 138: 130-145.

Bilgi MG (2013) Türkiye'nin Sakin Şehirlerinde Permakültürel Koruma, Planlama, Yönetim ve Eğitim Pratikleri. Selçuk Üniversitesi Sosyal Bilimler Enstitüsü Dergisi, 29: 45-59.

Bogatyrev NR, Bogatyreva OA (2015) Permaculture and TRIZ-Methodologies for Cross-Pollination Between Biology and Engineering. Procedia engineering, 131: 644-650.

Brown JG, Burger C (1984) Playground Designs and Preschool Children's Behaviors. Environment and behavior, 16 (5): 599-626.

Bulut Z, Yılmaz S (2008) Permaculture Playgrounds as a New Design Approach for Sustainable Society. International Journal of Natural \& Engineering Sciences, 2(2): 35-40.

Bulut Z, Kılıçaslan Ç (2011) Çocuğa Özgüven Kazandırmada Önemli Bir İlke; Çocuk Oyun Alanlarında Güvenlik. Artvin Çoruh Üniversitesi Orman Fakültesi Dergisi, 10 (1): 78-85.

Canlı GA (2014) Gelişen Dünyada Çağdaş Çocuk Oyun Alanları. Yayımlanmamış Yüksek Lisans tezi. Mimar Sinan Güzel Sanatlar Üniversitesi, İstanbul.

Coe DP, Flynn JI, Wolff DL, Scott SN, Durham S (2014) Children's Physical Activity Levels and Utilization of a Traditional Versus Natural Playground. Children Youth and Environments, 24 (3): 1-15.

Cohen S, Horm-Wingerd D (1993) Children and the Environment: Ecological Awareness Among Preschool Children. Environment and Behaviour, 25: 103-120.

Doherty M (2018) Permaculture in the Modern World: How Can We Apply the Integration of New Technology With Permaculture Practices in Suburban Neighborhoods to Reduce Waste and Increase Sustainability? . Department of Urban Horticulture and Design of the State University of New York, Farmingdale State College. December, Long Island, New York,32.

Ferguson RS Lovell ST (2004) Permaculture for agroecology: design, movement, practice, and worldview. A review. "Agronomy for Sustainable Development. 34, 251274.

Fjortoft I, Sageie J (2000) The Natural Environment as A Playground for Children Landscape Description and Analyses of A Natural Playscape. Landscape and Urban Planning, 48 (1-2): 83-97.

Fjortoft I (2001) The Natural Environment as a playground for children: The Impact of Outdoor Play Activities in Pre-Primary School Children. Early Childhood Education Journal, 29(2): 111-117.
Fjortoft I (2004) Landscape as Playscape: The Effects of Natural Environments on Children's Play and Motor Development. Children Youth and Environments,14(2):21-44.

Freeman C, Van Heezik Y (2018) Children, Nature and Cities: Rethinking the Connections. 305 . Routledge Taylor and Francis Group, New York.

Gemmell J (2015) Rethinking Playgrounds: A Design Investigation of Playscape Theory. Master Thesis, The Faculty of the Graduate School of the University of Maryland, College Park, in partial fulfillment of the requirements for the degree of Master of Landscape Architecture,76.

Ginsburg KR (2007) The Importance of Play in Promoting Healthy Child Development and Maintaining Strong Parent-Child Bonds. Pediatrics, 119(1): 182-191.

Haapala EA, Poikkeus A, Tompuri T, Kukkonen-Harjula K, Leppanen PH, Lindi V, Lakka TA (2014) Associations of Motor and Cardiovascular Performance With Academic Skills in Children. Medicine \& Science in Sports \& Exercise, 46(5):1016-1024.

Haluza-DeLay, R., \& Berezan, R. (2013). Permaculture in the city: Ecological habitus and the distributed ecovillage. In J. Lockyer \& J. R. Veteto (Eds.), Environmental anthropology engaging ecotopia (pp. 130-145). New York, NY: Berghan Books.

Hayward DG, Rothenberg M, Beasley RR (1974) Children's play and urban playground environments: a comparison of traditional, contemporary, and adventure playground types. Environment and Behavior, 6(2):131-168.

Hemenway T (2007) Permakültür Bahçeleri, Yeni İnsan Yayınevi, 16, 288, İstanbul. ISBN: 9789752498204.

Herrington S, Brussoni M (2015) Beyond Physical Activity: The Importance of Play and Nature-Based Play Spaces for Children's Health and Development. Current Obesity Reports, 4(4): 477-483.

Heseltine P., Holborn J (1987) Playgrounds. The Planning, Design and Construction of Play Environments, Page:11

Hirschfeld S, Van Acker R (2019) Permaculture Farmers Consistently Cultivate Perennials, Crop Diversity, Landscape Heterogeneity and Nature Conservation. Renewable Agriculture and Food Systems., 1-10. DOI: https://doi.org/10.1017/S1742170519000012 Published online by Cambridge University Press.

Holmgren D (2002) Permaculture. Principles and Pathways Beyond Sustainability. Holmgren Design Services, Hepburn, Victoria.

Holmgren D (2007) Essence of Permaculture. Hepburn: Holmgren Design Services, 23.

Huizinga J., (1995). Homo Ludens, oyunun toplumsal işlevi üzerine bir deneme. (Çev. Kılıçbay MA), Ayrıntı Yayınları, İstanbul, 16.

Jelinek R (2017) A Permaculture Primer: Using Eco-Theory to Promote Knowledge Acquisition, Dissemination 
and use in the Sales Organization. Industrial Marketing Management, 65: 206-216.

Kahl PH (1997) Developmental Psychology and The Biophilia Hypothesis: Children's Affiliation with Nature. Developmental Review, 17 (1): 1-61.

Kellert SR (2002) Experiencing Nature: Affective, Cognitive, and Evaluative Development in Children. In P. H. Khan, and S. R. Kellert, (Eds.), Children and Nature. Cambridge: MIT Press. 117-151.

Korn L (2003) Masanobu Fukuoka's Natural Farming and Permaculture. Retrieved April, 13, 2011.

Lester S, Russell W (2008) Play for a Change. Play Policy and Practice. A rewiev of contemporary perspectives London: Play Englland. National Children's Bureau.

Louv R (2010) Doğadaki Son Çocuk. Ankara: Çevirmen, Ceyhan Temürcü, TÜBiTAK Yayınları, 450.

Mollison B, Holmgren D (1978) Permaculture-1, Edition Debard. Australie.

Mollison B (1981) Introduction to Permaculture. Yankee Permaculture. USA.

Mollison B (1988) Permaculture : A Designers Manual. Tagari Publications . Australia.

Mollison B (1996) What is Permaculture?. Proceedings of the Sixth International Permaculture Conference, 5, Australia

Moore R, Young D (1978) Childhood Outdoors: Toward a Social Ecology of the Landscape. In Children and the Environment . Springer, Boston, MA,83-130.

Najafıdashtape A, Hamamcıoğlu C (2018) Sorumlu Üretim ve Tüketim Bağlamında Permakültür ve Kentsel Açık ve Yeşil Alan İlişkisi. Mimarlık Bilimleri ve Uygulamaları Dergisi, 3(1): 1-17.

Navarro EP (2018) Networked Playscapes: Redefining the Playground . Doctoral dissertation, Massachusetts Institute of Technology.

Pesce C, Masci I, Marchetti R, Vazou S, Saakslahti A, Tomporowski PD (2016) Deliberate Play and Preparation Jointly Benefit Motor and Cognitive Development: Mediated and Moderated Effects. Frontiers in Psychology, 7: 1-17.

Pezrès E., 2010, " La permaculture au sein de l'agriculture urbaine : du jardin au projet de société ", VertigO - La Revue électronique en sciences de l'environnement 10 (2) DOI:10.4000/vertigo.9941 Polat Z (2018) Assessment of Today's Playgrounds With Permaculture Playground Desıgn Prıncıples: Case of Aydın, Turkey. Recent Researches in Education, 469.

Polat Z (2018) Assessment of Today's Playgrounds with Permaculture Playground Design Principles: Case of Aydın, Turkey. Resent Researches in Science and Landscape Management. Edited by Recep Efe, Murat Zencirkıran and İsa Curebal. Cambiridge Scholars Publishing. Chapter 35, 469-481. ISBN(10):1-52751087-5.

Pollard A, Thiessen D, Filer A (1997) Children and Their Curriculum: The Perspectives of Primary and Elementary School Children. The Falmer Press. 0750705949, 9780750705943, 206.
ÜSKÜPLÜ EM, POLAT Z

Powell KE (2005) Land Use, The Built Environment, And Physical Activity: A Public Health Mixture; A Public Health Solution. Amerikan Journal of Preventive Medicine, 28 (252), $216-217$

Praetorius P (2006) A Permaculture School Garden. Green teacher, 78(6).

Raney MA, Hendry CF, Yee SA (2019) Physical Activity and Social Behaviors of Urban Children in Green Playgrounds. American Journal of Preventive Medicine, 56(4): 522-529.

Rhodes CJ (2012) Feeding and Healing the World: Through Regenerative Agriculture and Permaculture. Science Progress, 95(4): 345-446.

Said I, Bakar MSA (2005) Landscape for Children to Play and Learn: A Conceptual Comparison Between Natural Stream and Playground. Jurnal Teknologi, 42(1): 1-10.

Salleh AM, Rosli FM, Esa N, Ibrahim MH (2018) Permaculture Design: Linking Local Knowledge in Land Use Planning for House Compound. In SHS Web of Conferences (Vol. 45, p. 03003). EDP Sciences.

Sandseter EBH, Kennair LEO (2011) Children's risky play from an evolutionary perspective: The anti-phobic effects of thrilling experiences. Evolutionary Psychology, 9(2), 257-284.

Sarı SÇ (2011) Çocuk Oyun ve Öğrenme. Eğitime Bakış, 20(7): 21-25.

Seefeldt C, Galper A (2007) "Sciencing" and Young Children. Scholastic Early Childhood Today, 12-13.

Simonon L (2000) Permaculture playgrounds. Playlines, 8 (21).

Stark PL (2009) Penny Livingston Stark ile Permakültür Çalıştayı. Regenerative Design Institute, Bolinas, California.

Taştepe T, Başbay AM, Yazıcı Z (2016) Kent Merkezlerindeki Ekolojik Çocuk Oyun Alanlarının Mekansal Açıdan İncelenmesi: Ankara-Antalya Örneği. JOTAF/Tekirdağ Ziraat Fakültesi Dergisi, 13(2): 85-95.

Tatar S, Olay N (2015) Agro-Turizm Kapsamında Permakültür'ün Uygulanabilirliği ve Geliştirilmesi: Belentepe Permakültür Çiftliği Örneği. Uluslararası Sosyal ve Ekonomik Bilimler Dergisi 5 (2): 29-34.

Veteto JR, Lockyer J (2008) Environmental Anthropology Engaging Permaculture: Moving Theory and PracticeToward Sustainability. Culture \& Agriculture 30(1-2): 47-58.

Wallace M, Carruthers D (Eds.) (2018) Perma/culture: Imagining Alternatives in an Age of Crisis. Routledge Taylor and Francis Group, New York, 238.

Walsh P (2016) Early Childhood Playgrounds: Planning an Outside Learning Environment. Routledge, 120. ISBN: 978-1-138-85941-8.

Wang X, Woolley H, Tang Y, Liu HY, Luo Y (2018) Young Children's and Adults' Perceptions of Natural Play Spaces: A Case Study of Chengdu, Southwestern China. Cities, 72: 173-180.

Wells NM (2000) At Home With Nature: Effects of 'greenness' on children's cognitive functioning. Environment and Behavior, 32 (6): 775-795. 
White R, Stoecklin V (1998) Children's outdoor play \& learning environments: Returning to nature. Early Childhood News, 10(2): 24-30.

White R (2004) Young children's relationship with nature: Its importance to children's development \& the earth's future. White Hutchinson Leisure \& Learning Group, 1-9.

Yao K (2015) Playground Utilization: A Study on Urban, Community and Neighborhood Park Playgrounds in Manhattan, Kansas. MSc. Thesis, Kansas State University, Manhattan, 1. 